\title{
Understanding barriers to fruit and vegetable intake in the Australian Longitudinal Study of Indigenous Children: a mixed-methods approach
}

\author{
Katherine Ann Thurber ${ }^{1, *}$, Cathy Banwell ${ }^{1}$, Teresa Neeman ${ }^{2}$, Timothy Dobbins ${ }^{3}$, \\ Melanie Pescud ${ }^{4,5}$, Raymond Lovett ${ }^{1}$ and Emily Banks ${ }^{1}$ \\ ${ }^{1}$ National Centre for Epidemiology and Population Health, Research School of Population Health, The Australian \\ National University, 62 Mills Road, Acton, ACT 2601, Australia: ${ }^{2}$ Statistical Consulting Unit, The Australian \\ National University, Acton, ACT, Australia: ${ }^{3}$ National Drug \& Alcohol Research Centre, University of New South \\ Wales, Randwick, NSW, Australia: ${ }^{4}$ RegNet School of Regulation and Global Governance, The Australian National \\ University, Acton, ACT, Australia: ${ }^{5}$ The Australian Prevention Partnership Centre, Sax Institute, Ultimo, NSW, \\ Australia
}

Submitted 26 April 2016: Final revision received 26 September 2016: Accepted 29 September 2016: First published online 29 November 2016

\begin{abstract}
Objective: To identify barriers to fruit and vegetable intake for Indigenous Australian children and quantify factors related to these barriers, to help understand why children do not meet recommendations for fruit and vegetable intake.

Design: We examined factors related to carer-reported barriers using multilevel Poisson models (robust variance); a key informant focus group guided our interpretation of findings.

Setting: Eleven diverse sites across Australia.

Subjects: Australian Indigenous children and their carers ( $N 1230)$ participating in the Longitudinal Study of Indigenous Children.

Results: Almost half ( $45 \% ; n$ 555/1230) of carers reported barriers to their children's fruit and vegetable intake. Dislike of fruit and vegetables was the most common barrier, reported by $32.9 \%$ of carers; however, we identified few factors associated with dislike. Carers were more than ten times less likely to report barriers to accessing fruit and vegetables if they lived large cities $v$. very remote areas. Within urban and inner regional areas, child and carer well-being, financial security, suitable housing and community cohesion promoted access to fruit and vegetables.

Conclusions: In this national Indigenous Australian sample, almost half of carers faced barriers to providing their children with a healthy diet. Both remote/outer regional carers and disadvantaged urban/inner regional carers faced problems accessing fruit and vegetables for their children. Where vegetables were accessible, children's dislike was a substantial barrier. Nutrition promotion must address the broader family, community, environmental and cultural contexts that impact nutrition, and should draw on the strengths of Indigenous families and communities.
\end{abstract}

Keywords
Diet, food and nutrition
Child health
Holistic health
Health behaviour
Poor diet is the leading preventable risk factor for poor health in Australia, estimated to account for more than $10 \%$ of the total burden of disease ${ }^{(1)}$, including through its association with conditions including cardiovascular and circulatory diseases, cancer and diabetes. The disease burden attributable to poor diet is estimated to be nearly double (19\%) in the Indigenous population; four of the seven leading risk factors contributing to the gap in health between the Indigenous and non-Indigenous populations relate to diet (obesity, high blood cholesterol, high blood pressure, low fruit and vegetable intake) ${ }^{(2)}$.

Australian guidelines recommend that children aged $4-8$ years consume $1 \frac{1}{2}$ servings of fruit and $4 \frac{1}{2}$ servings of vegetables daily, increasing to 2 and 5 servings daily, respectively, for children aged 9-11 years ${ }^{(3)}$. Data from a 2012-2013 national survey indicated that while $78 \%$ of Indigenous children met recommendations for fruit intake, only $16 \%$ met recommendations for vegetable intake ${ }^{(4)}$, 
consistent with statistics for non-Indigenous Australian children $^{(5)}$. Increasing fruit and particularly vegetable intake by Indigenous children could decrease the burden of disease. However, there is limited evidence on the effectiveness of existing programmes and policy to improve Indigenous nutrition ${ }^{(6)}$.

Indigenous Australians have a diversity of cultures and live in varied environments ${ }^{(7)}$. About $57 \%$ of the Indigenous population lives in major cities or inner regional areas (approximately 380800 people) and $21 \%$ in remote or very remote settings (approximately 142900 people), compared with $90 \%$ and $2 \%$ of the non-Indigenous population, respectively ${ }^{(8)}$. On average, Indigenous Australians have lower socio-economic status than non-Indigenous Australians, and are more likely to live in homes that are overcrowded or have infrastructure problems ${ }^{(9,10)}$ and to live in areas of socio-economic deprivation ${ }^{(11)}$.

Food choice is complex and influenced by a broad range of factors ${ }^{(12-15)}$. The ability to purchase fruit and vegetables is influenced by their accessibility, affordability and availability; in Australia, basic healthy food items are less likely to be available and more likely to be more expensive and of lower quality in remote areas compared with urban centres ${ }^{(16-18)}$. Food purchasing behaviour is strongly associated with socio-economic status and is also shaped by individual preferences and cultural factors $^{(12,13,17,19-22)}$. Connection and commitment to extended family and community members, and community organisations and events have been identified as factors supporting Indigenous well-being ${ }^{(23,24)}$. For example, cultural values and norms about reciprocity and generosity encourage Indigenous families to share food and resources with others ${ }^{(25)}$; many households often feed extra people ${ }^{(12,26,27)}$ and 'humbugging', wherein relatives or friends request money or resources, is a common practice in some communities ${ }^{(25,28)}$. Traditional knowledge and food systems are also understood to promote Indigenous nutrition ${ }^{(29)}$; however, these were disrupted through colonisation and its lasting impacts on the Indigenous population, resulting in profound changes to Indigenous food practices ${ }^{(13,26,30,31)}$. Contemporarily, market foods are estimated to generally constitute the majority of food intake by Indigenous Australians, with 'bush tucker' (hunted and cultivated traditional foods) a minor contributor to intake $e^{(29,32-34)}$.

Overall, Indigenous children disproportionately face barriers to fruit and vegetable intake compared with non-Indigenous children, given the population distribution, lower socio-economic status, and unique historical, political and cultural context. Qualitative research in both remote and urban settings has depicted how broader social, cultural and environmental factors influence Indigenous Australians' food choice ${ }^{(12,13,17,19,20)}$. The purpose of the current work was to quantify factors related to perceived barriers to fruit and vegetable intake for Indigenous Australian children, in order to understand why children do not meet recommendations for intake. We have focused on identifying protective (rather than risk) factors that facilitate children's consumption of fruit and vegetables. Within this, we explore variation between urban, regional and remote settings, given the vast differences in food environments, population characteristics and cultural contexts.

\section{Methods}

\section{Mixed methods}

The current study analyses quantitative data from the Longitudinal Study of Indigenous Children (LSIC) and qualitative data from a key informant focus group. Rather than relying on quantitative epidemiological analyses on their own, we conducted a focus group as part of our research protocol to guide data interpretation ${ }^{(35)}$. This mixed-methods approach ${ }^{(36)}$ facilitates a more holistic analysis, considering multiple perspectives and drawing on multiple ways of sharing knowledge ${ }^{(37,38)}$, and enhances the interpretation and contextualisation of findings ${ }^{(35)}$. Our approach was guided by Bronfenbrenner and Morris' social ecological model ${ }^{(39)}$ and a conceptual framework applied within the Pro Children project ${ }^{(40,41)}$.

\section{Study population}

The LSIC is a national study managed by the Australian Government's Department of Social Services ${ }^{(42)}$. Purposive sampling was used to recruit Aboriginal and Torres Strait Islander children from eleven diverse sites across Australia. The survey design and the implications for analysis have been described elsewhere ${ }^{(42,43)}$. Indigenous Research Administration Officers (RAOs) conduct annual face-to-face interviews with children and their primary carer (the child's mother in the majority of cases, or sometimes the father, a relative or other guardian). The present analysis is based on data collected in 2013, in Wave 6 of the LSIC. The primary carer reported all data included in the analysis, with the exception of children's BMI, which was calculated based on height and weight measurements taken by RAOs, and remoteness and arealevel disadvantage, which were derived from participants' addresses.

\section{Focus group methods}

In February 2015, the lead author (K.A.T.), a nonIndigenous woman, conducted a focus group with the RAOs currently conducting LSIC interviews ( $n$ 12/12). As all RAOs are Indigenous and most live in the sites in which they conduct interviews, we considered them key informants in these communities, holding pertinent contextual knowledge ${ }^{(35)}$.

The focus group was semi-structured to facilitate the sharing of stories and to allow new issues to emerge throughout the discussion ${ }^{(44)}$; the participants guided the 
depth and focus of discussion on each topic. During the focus group, K.A.T. presented preliminary descriptive analysis of the relevant LSIC data, including: the distribution of carer-reported fruit and vegetable intake by children, overall and by remoteness; carer-reported barriers to children's fruit and vegetable intake, overall and by remoteness; examples of carers' free-text responses about why their children did not eat more fruit and vegetables; and examples of carers' free-text responses about how they encouraged their children to eat more fruit and vegetables. For each item, K.A.T. asked RAOs to comment if this was consistent with the experience they had in the site in which they worked, if they thought the findings were important and what they thought the findings meant. RAOs were encouraged to share stories and experiences from the field.

K.A.T. conducted, transcribed and analysed the focus group interview, which was audio-recorded with participants' content. The LSIC team reviewed and approved the transcript; a follow-up discussion was held with the RAOs in 2016 to discuss the interpretation of final results and their implications.

\section{Variables in the quantitative analysis}

\section{Exposures}

Child factors. We examined children's age at the time of survey, sex, and identification as Aboriginal, Torres Strait Islander or both. We also examined indicators of the child's well-being: general health, social and emotional well-being (low/moderate $v$. high risk of social and emotional behavioural difficulties according to the Strengths and Difficulties Questionnaire $\left.{ }^{(45,46)}\right)$, and BMI category $^{(47,48)}$.

Family factors. We examined objective and subjective measures of families' financial situations: carer's relationship status, weekly household income, financial strain (run out of money before payday/spending more than earning; enough money to get through to the next payday; can save a bit/a lot), serious worries about money in past year, food insecurity (going without meals because of a lack of money) in the past year, and carer's highest qualification and employment status. We examined indicators of resource sharing: being humbugged in the past year, frequency of feeding others who don't live at home and pressures to support others in the community.

We also examined carers' general health and social and emotional well-being (low or high distress, based on a social and emotional well-being index ${ }^{(49)}$ ) and the number of negative major life events experienced by the family in the past year.

We examined whether the family had an evening meal together in the past week and carers' perceptions of the importance of passing on cultural knowledge to their children about bush tucker, hunting and fishing. We also examined household size and housing problems (home has felt too crowded in past year; moved house in past year; problems with fridge and/or cooking facilities; major electrical problems at home; security problems at home major problems with locks, windows, doors or screens).

Area-level factors. Geographical remoteness in the LSIC is measured using the Level of Relative Isolation scale ${ }^{(50)}$. Areas are categorised as having no, low, moderate, high or extreme isolation; these categories correspond to major cities, larger regional centres, smaller regional centres far from large cities and communities/settlements generally with a predominantly Indigenous population, respectively. For stratified analyses, we classified areas with no or low isolation as urban/inner regional (urban/IR) and areas with moderate or high/extreme isolation as remote/outer regional (remote/OR).

Area-level disadvantage was measured using the Index of Relative Indigenous Socioeconomic Outcomes $(\text { IRISEO })^{(51)}$, an index calculated specifically for Indigenous Australians based on nine measures of socio-economic status. We categorised areas as having the highest level of advantage (IRISEO 8-10), mid-level advantage (IRISEO 4-7) and the lowest level of advantage (IRISEO 1-3).

Carers also reported if they experienced a problem with racially motivated violence, alcohol misuse, and break-ins or theft in their community.

See the online supplementary material, Supplemental File 1, for more details on exposure variables.

\section{Outcome}

All carers were asked if they would like their children to eat more fruit and/or vegetables. Carers responding that they wanted their children to eat more were asked to select up to two barriers to their child's fruit and/or vegetables intake: 'child doesn't like them or refuses to eat them', 'too expensive', 'not readily available (e.g. shop doesn't have enough)', 'poor quality of fresh produce', 'issue with transport (e.g. shop too far away or no car)', 'no food preparation area or storage', 'don't know' or 'other'. Carers reporting barriers related to accessibility, affordability and availability ('too expensive', 'not readily available', 'poor quality', 'issue with transport', 'no food preparation area or storage') were categorised as perceiving accessibility-related barriers. Carers responding that their children 'had enough' fruit and vegetables were considered to perceive no barriers to intake. Carers who responded 'don't know' $(0 \cdot 4 \%, n 5 / 1239)$ or who specified a different answer $(0.3 \%, n$ 4/1239) were excluded.

To ensure that our outcome variable was meaningful, we validated that carers' perceptions of barriers reflected low fruit and vegetable intake by their children, and that the relationships of exposures to carers' perception of barriers were consistent with the relationships of these exposures to children's low vegetable intake. This validation was conducted within the sample of children ( $n$ 502/1230) who had data on dietary intake (see online supplementary material, Supplemental File 2). 


\section{Analytical methods}

Rather than looking at factors relating to carers' perception of any barriers, we separately examined factors related to accessibility barriers and factors related to children's dislike of fruit and vegetables, as the factors related to these two barrier types might vary. It is difficult to interpret dislike if children have limited access to fruit and vegetables, or if they only have access to fruit and vegetables that are of poor quality, so we examined factors related to children's dislike in the sample restricted to those without any accessibility barriers.

We calculated prevalence ratios (PR) using multilevel Poisson models with robust variance. Children's geographic cluster was included as a level variable to account for the within-cluster correlation resulting from the LSIC's survey design. We first adjusted these models for age group and sex only. We expected that remoteness might confound these relationships, given known variation in food availability and sociocultural context across levels of remoteness, so we repeated the models with additional adjustment for remoteness and examined how this altered relationships. If findings indicated potential residual confounding by remoteness, we repeated analyses separately in the urban/IR and remote/OR groups. We tested if the exposure-outcome relationships varied between urban/IR and remote/OR environments by repeating the models in the whole sample including an interaction term between the dichotomous remoteness variable and the exposure, with $P_{\text {interaction }}<0.05$ indicating a significant difference.

Analysis of the qualitative data from the focus group guided our interpretation of quantitative findings ${ }^{(35)}$. The qualitative data were analysed thematically ${ }^{(52)}$. Inductive and deductive codes were developed based on our open-ended questions and refined as new information was found. Coded textual segments were grouped into categories and sub-categories which were then developed into themes ${ }^{(53)}$ and further refined and cross-checked through discussions within the team. The qualitative findings reported in the present manuscript reflect the outcomes of the group discussion and the unique viewpoints of RAOs working in different settings.

\section{Ethics}

The LSIC survey was conducted with ethical approval from the Departmental Ethics Committee of the Australian Commonwealth Department of Health and from relevant Ethics Committees in each state and territory, including relevant Aboriginal and Torres Strait Islander organisations. The Australian National University's Human Research Ethics Committee granted ethics approval for the quantitative analysis of LSIC data in October 2011 (protocol number 2011/510); approval to conduct the focus group and for subsequent engagement with key informants was granted in 2015 and 2016, respectively.

\section{Results}

\section{Profile of the sample}

Interviews were conducted with 1239 carers in LSIC Wave 6, of whom 1230 provided data on barriers to their children's fruit and vegetable intake. Children in the younger cohort were aged 4-6 years and children in the older cohort were aged 7-10 years; 614 female and 616 male children were included in the sample. The majority of families in the sample were living in urban/IR areas, $78.7 \%$ ( $n$ 968/1230), with 21.3\% ( $n$ 262/1230) living in remote/OR areas. Characteristics of the participating families are presented in Table 1 .

On average, carers reported that children in the older cohort consumed $2 \cdot 1$ servings of fruit daily, with about

Table 1 Profile of families participating in the Australian Longitudinal Study of Indigenous Children (LSIC), Wave 6, 2013

\begin{tabular}{|c|c|c|c|c|c|c|}
\hline & \multicolumn{2}{|c|}{ Remote/OR ( $N$ 262) } & \multicolumn{2}{|c|}{ Urban/IR ( $N$ 968) } & \multicolumn{2}{|c|}{ Total $(N$ 1230) } \\
\hline & $\%$ & $n / N$ & $\%$ & $n / N$ & $\%$ & $n / N$ \\
\hline Carer is partnered & 58.0 & $152 / 262$ & 54.7 & $529 / 968$ & 55.4 & $681 / 1230$ \\
\hline Carer has education Year 12 or further & 39.5 & $92 / 233$ & 44.4 & $399 / 899$ & 43.4 & $491 / 1132$ \\
\hline Household income $\geq \$$ AU 600/week & $47 \cdot 3$ & $104 / 220$ & 63.7 & $581 / 912$ & 60.5 & $685 / 1132$ \\
\hline Family has not been humbugged in past year & $60 \cdot 2$ & $157 / 261$ & $75 \cdot 8$ & $733 / 967$ & $72 \cdot 5$ & $890 / 1228$ \\
\hline No problem with pressure to support others in the community & $51 \cdot 0$ & $126 / 247$ & $79 \cdot 8$ & $700 / 877$ & 73.5 & $826 / 1124$ \\
\hline Household size $\geq 6$ members & $52 \cdot 3$ & $137 / 262$ & 35.4 & $343 / 968$ & $39 \cdot 0$ & $480 / 1230$ \\
\hline Households with working fridge and cooking facilities & $82 \cdot 7$ & $143 / 173$ & $95 \cdot 0$ & $667 / 702$ & 92.6 & $810 / 875$ \\
\hline Living in areas in highest tertile of advantage & $3 \cdot 8$ & $10 / 262$ & $25 \cdot 9$ & $251 / 968$ & $21 \cdot 2$ & $261 / 1230$ \\
\hline Older cohort only ( $N 495)$ & Mean & $95 \% \mathrm{Cl}$ & Mean & $95 \% \mathrm{Cl}$ & Mean & $95 \% \mathrm{Cl}$ \\
\hline $\begin{array}{l}\text { Number of usual daily servings of fruit } \\
n\end{array}$ & $2 \cdot 1$ & $\begin{array}{c}1 \cdot 9,2 \cdot 3 \\
99\end{array}$ & $2 \cdot 1$ & $\begin{array}{c}2 \cdot 0,2 \cdot 2 \\
394\end{array}$ & $2 \cdot 1$ & $\begin{array}{c}2 \cdot 0,2 \cdot 2 \\
493\end{array}$ \\
\hline $\begin{array}{l}\text { Number of usual daily servings of vegetables } \\
n\end{array}$ & $1 \cdot 8$ & $\begin{array}{c}1 \cdot 6,2 \cdot 1 \\
99\end{array}$ & 1.9 & $\begin{array}{l}1 \cdot 7,2 \cdot 0 \\
396\end{array}$ & 1.9 & $\begin{array}{c}1 \cdot 8,2 \cdot 0 \\
495\end{array}$ \\
\hline
\end{tabular}

The sample includes those with data on barriers. Data on intake of fruit and vegetables were recorded for the older cohort (children aged 7-10 years) only. Sample size varies due to missing data on the exposures of interest.

Urban/inner regional (urban/IR) areas were defined as those with no or low isolation (major cities and larger regional centres) and remote/outer regional (remote/ $\mathrm{OR}$ ) areas as those with moderate or high/extreme isolation (smaller regional centres far from large cities and communities/settlements generally with a predominantly Indigenous population). 
$80 \%$ meeting the recommended daily intake for their age group. Vegetable intake was much lower in the sample, with less than $5 \%$ of children meeting their recommended daily intake; on average, carers reported that children consumed 1.9 servings of vegetables daily. We did not observe significant variation in intake between remote/OR and urban/IR settings.

\section{Reported barriers}

Almost half of carers ( $45 \cdot 1 \% ; n$ 555/1230) reported a barrier to their child's fruit and vegetable intake (Table 2); $17.5 \%$ ( $n$ 215) reported barriers to vegetable intake only, $4.1 \%(n 51)$ reported barriers to fruit intake only, and $23.5 \%$ ( $n$ 289) reported barriers to both fruit and vegetable intake. In the following analyses, we have examined barriers to fruit and vegetable intake combined.

Children's dislike of fruit and/or vegetables was the most common barrier, reported by 32.9\% ( $n$ 405/1230) of carers. An additional $7.4 \%$ of carers reported barriers related to accessibility: $4 \cdot 1 \%(n$ 51/1230) said fruit and vegetables were too expensive, $\leq 3 \cdot 2 \%(n \leq 39 / 1230)$ said they were not available, $\leq 2.3 \%(n \leq 28 / 1230)$ said they were of poor quality, $0.7 \%(n 9 / 1230)$ reported issues with transport and $\leq 0.5 \%(n \leq 6 / 1230)$ said that food preparation or storage areas were not available. Few carers (1.2\%; $n$ 15/1230) reported barriers related to both dislike and accessibility.

An additional $6.7 \%$ of carers specified other reasons ( $n$ 82/1230 carers providing ninety-four total responses), with the main themes of: fussy eating and children making their own choices ( $n$ 20); carers' cooking and eating habits, including time constraints ( $n$ 14); the preparation or appearance of fruit and vegetables ( $n 9$ ); dietary restrictions due to disability or health conditions ( $n 9$ ); the type or variety of fruit and vegetables available ( $n$ 8); 'running out' of fruit and vegetables at home quickly, or not purchasing enough $(n 7)$; and competition from alternatives such as junk food $(n 6)$.
The proportion of carers reporting any barriers to the child's fruit and vegetable consumption was $48.1 \%$ in remote/OR and $44.3 \%$ in urban/IR areas. Children's dislike of fruit and vegetables was the most common barrier in both settings, but barriers related to accessibility were more commonly reported by remote/OR carers (Table 2 and Fig. 1). In remote/OR settings, $24.8 \%$ ( $n$ 65/262) of carers reported children's dislike, $24.0 \%$ ( $n$ 63/262) reported any accessibility barriers and $2 \cdot 7 \%(n$ 7/262) specified other reasons. In urban/IR settings, $35 \cdot 1 \%$ ( $n$ 340/968) of carers reported children's dislike, $2.9 \%$ ( $n$ 28/968) reported any

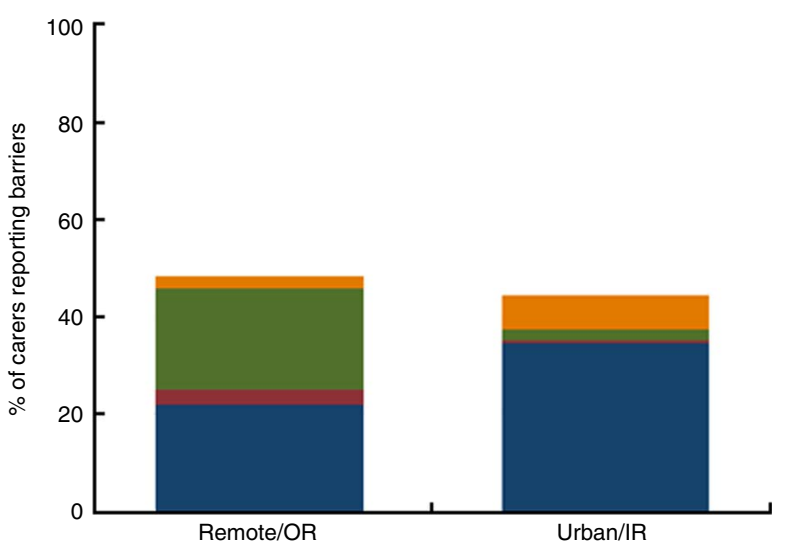

Fig. 1 (colour online) Categories of carer-reported barriers to children's fruit and vegetable consumption in urban/inner regional (urban/IR) and remote/outer regional (remote/OR) settings among families participating in the Australian Longitudinal Study of Indigenous Children (LSIC), Wave 6, 2013 (N 1230). Responses were categorised as 'Child dislike only' $(\square)$ if the only barrier the carer reported was that the child did not like fruit and/or vegetables; 'Accessibility only' $(\square)$ if the carer only reported barriers related to accessibility and availability (too expensive, not available, poor quality, transport issues, and no storage); 'Accessibility + child dislike' $(\square)$ if the carer reported children's dislike and a barrier related to accessibility or availability; or 'Other, don't know or refused only' ( $\square$ )

Table 2 Barriers to children's fruit and vegetable consumption reported by carers in the Australian Longitudinal Study of Indigenous Children (LSIC), Wave 6, 2013 
accessibility barriers and $7 \cdot 7 \%$ ( $n$ 75/968) specified other reasons.

\section{Factors associated with accessibility barriers}

Accessibility barriers were strongly associated with remoteness. The percentage of carers reporting an accessibility barrier increased from $2.0 \%(n 7 / 348)$ in areas with the lowest level of remoteness to $33.7 \%(n$ 35/104) in areas with the highest level of remoteness, corresponding to a greater than tenfold increased prevalence after adjustment for age and sex (PR=14.1, 95\% CI 4.3, 46.4). The magnitude of these differences indicated that simply adjusting for remoteness might result in residual confounding by remoteness, so we present the analyses stratified by remote/OR $v$. urban/IR status (see online supplementary material, Supplemental File 3, for unstratified results).

\section{Remote/outer regional areas}

Within remote/OR areas, accessibility barriers were significantly associated with indicators of family financial status, resource sharing and housing, as well as community-level factors (Table 3). Remote/OR carers were significantly less likely to report accessibility barriers if they did not experience food insecurity in the past year (20.3 v. 59.3\%; PR=0.6, 95\% CI 0.4, 0.9), were not humbugged in the past year (16.6v. 35.6\%; PR=0.6, $95 \%$ CI $0.4,1.0)$ and did not have electrical problems at home (21.4 v. 64.7\%; PR = 0.7, $95 \%$ CI 0.5, 0.9). Carers who lived in communities where racially motivated violence was not a problem $(23.2 v .46 \cdot 7 \%$; $\mathrm{PR}=0.8,95 \% \mathrm{CI} 0 \cdot 7,1 \cdot 0)$, or in areas with higher levels of advantage, were significantly less likely to report accessibility barriers. Carers who considered it important to teach their children about bush tucker were more likely to report accessibility barriers than carers who did not consider it important.

\section{Urban/inner regional areas}

Although the absolute prevalence of accessibility barriers was much lower for carers in urban/IR $v$. remote/OR areas, we observed pronounced factors associated with accessibility barriers within the urban/IR group (Table 3). Advantage at both the family and area level was associated with a substantially lower prevalence of accessibility barriers. For example, the risk of accessibility barriers was reduced more than tenfold for urban/IR carers who reported they usually could save money $v$. ran out of money before the next payday $(0.5 v \cdot 6 \cdot 7 \% ; \mathrm{PR}=0 \cdot 1,95 \% \mathrm{CI} 0 \cdot 0,0.3)$ and who lived in areas with highest $v$. lowest tertile of advantage ( $\leq 1 \cdot 2 v \cdot 13 \cdot 8 \% ; \mathrm{PR}=0 \cdot 1,95 \% \mathrm{CI} 0 \cdot 0,0 \cdot 3)$. We also observed a lower prevalence of accessibility barriers among carers who were partnered ( $1.9 v .4 \cdot 1 \%$; PR $=0 \cdot 4,95 \% \mathrm{CI} 0 \cdot 2,0 \cdot 8)$, who had weekly incomes $\geq \$$ AU $600 v$. $<\$$ AU 600 (2.1 $v$. $4.5 \%$; PR $=0.5,95 \%$ CI $0.3,0.9)$ and who did not report worries about money $(2 \cdot 1 v .4 \cdot 9 \% ; \mathrm{PR}=0 \cdot 4,95 \% \mathrm{CI} 0 \cdot 2,0 \cdot 7)$ or experience food insecurity (2.4 v. $13 \cdot 3 \%$; $\mathrm{PR}=0.3,95 \%$ CI $0 \cdot 1,0 \cdot 8)$ in the past year.
Factors related to the sharing of resources were also significantly associated with accessibility barriers; carers were significantly less likely to report accessibility barriers if they were not humbugged in the past year (1.9 v. 6.0\%; $\mathrm{PR}=0 \cdot 4,95 \% \mathrm{CI} 0 \cdot 2,0 \cdot 9)$ and if they were not pressured to support others in their community (1.6 v. 7.3\%; PR=0.3, $95 \%$ CI $0 \cdot 1,0 \cdot 6$ ). Urban/IR carers were also less likely to report accessibility barriers if they did not experience issues with their housing $(\mathrm{PR}=0.3,95 \% \mathrm{CI} 0 \cdot 2,0.7$ for overcrowding; $\mathrm{PR}=0 \cdot 2,95 \% \mathrm{CI} 0 \cdot 1,0 \cdot 4$ for problems with cooking facilities; PR $=0.4,95 \%$ CI $0 \cdot 2,0.9$ for problems with home security).

Carers living in urban/IR areas were less likely to report accessibility barriers if they or their children had good social and emotional well-being, and if they lived in communities without racially motivated violence $(2 \cdot 1 \mathrm{v}$. $5 \cdot 6 \% ; \mathrm{PR}=0 \cdot 2,95 \% \mathrm{CI} 0 \cdot 1,0 \cdot 6)$ or alcohol misuse (1.6 $v$. $4.9 \% ; \mathrm{PR}=0.4,95 \% \mathrm{CI} 0 \cdot 2,0 \cdot 9)$. As observed in remote/ OR areas, urban/IR carers who considered it important to teach their children about bush tucker were more likely to report accessibility barriers than carers who did not consider it important.

Similarities and differences in remote/outer regional $\mathrm{v}$. urban/inner regional areas

In most cases, the relationship between exposures and accessibility barriers was consistent within the urban/IR and remote/OR samples, although the magnitudes of effect were often much larger for the urban/IR $v$. remote/ OR group. However, we did observe that some exposures were differentially associated with accessibility barriers for carers in urban/IR compared with remote/OR environments $\left(P_{\text {interaction }}<0.05\right)$; this occurred for child and carer social and emotional well-being, carer's relationship status, financial strain, worries about money, problems with racially motivated violence, overcrowding and problems with cooking facilities in the home. In all but one of these cases, we observed a significant association between the exposure and accessibility barriers in the urban/IR sample, but a null relationship in the remote/OR sample. In the case of racially motivated violence, the relationship was significant in both the urban/IR and remote/OR samples, but the effect size was markedly greater in the urban/IR sample. We did not calculate the $P$ value for interaction between the dichotomous remoteness variable and the child's Indigenous identification, given the small number of Torres Strait Islander children living in urban/IR areas.

\section{Factors associated with children's dislike of fruits and vegetables}

Among carers who did not report barriers related to accessibility, we observed few factors significantly associated with children's dislike of fruit and vegetables (Table 4). After adjustment for age, sex and remoteness, carers were less likely to report dislike as a barrier if their 
Table 3 Factors associated with carers perceiving accessibility-related barriers to children's fruit and/or vegetable intake, according to remoteness, in the Australian Longitudinal Study of Indigenous Children (LSIC), Wave 6, 2013

\begin{tabular}{|c|c|c|c|c|c|c|c|c|}
\hline & \multicolumn{4}{|c|}{ Remote/OR } & \multicolumn{4}{|c|}{ Urban/IR } \\
\hline & $\%$ & $n / N$ & PR & $95 \% \mathrm{Cl}$ & $\%$ & $n / N$ & PR & $95 \% \mathrm{Cl}$ \\
\hline Total & $24 \cdot 1$ & $63 / 262$ & - & - & $2 \cdot 9$ & $28 / 968$ & - & - \\
\hline \multicolumn{9}{|l|}{ Child factors } \\
\hline \multicolumn{9}{|l|}{ Sex } \\
\hline Male & $21 \cdot 6$ & $27 / 125$ & 1.00 & & 3.7 & $18 / 491$ & 1.00 & \\
\hline Female & $26 \cdot 3$ & $36 / 137$ & 1.03 & $0.78,1.37$ & $2 \cdot 1$ & $10 / 477$ & 0.57 & $0.26,1.27$ \\
\hline \multicolumn{9}{|l|}{ Age group } \\
\hline $4-5$ years & $26 \cdot 4$ & $14 / 53$ & 1.00 & & $4 \cdot 1$ & $9 / 222$ & 1.00 & \\
\hline $6-7$ years & $24 \cdot 1$ & $27 / 112$ & $1 \cdot 10$ & $0.74,1.65$ & 2.5 & 9/355 & 0.60 & $0.24,1.52$ \\
\hline $8-10$ years & $22 \cdot 7$ & 22/97 & 0.85 & $0.57,1.26$ & $2 \cdot 6$ & $10 / 391$ & 0.70 & $0.32,1.53$ \\
\hline \multicolumn{9}{|l|}{ Indigenous identification†,§ } \\
\hline Aboriginal & $29 \cdot 1$ & $55 / 189$ & 1.00 & & $3 \cdot 1$ & $27 / 881$ & 1.00 & \\
\hline Torres Strait Islander & $\leq 6 \cdot 1$ & $\leq 3 / 49$ & 0.45 & $0.08,2.49$ & $\leq 7 \cdot 9$ & $\leq 3 / 38$ & 0.00 & $0.00,0.00$ \\
\hline Both & $20 \cdot 8$ & $5 / 24$ & 0.91 & $0.38,2 \cdot 19$ & $\leq 6 \cdot 1$ & $\leq 3 / 49$ & 0.52 & $0.05,5.21$ \\
\hline \multicolumn{9}{|l|}{ General physical health } \\
\hline Poor, fair, or good & $36 \cdot 5$ & $42 / 115$ & 1.00 & & 4.8 & 9/189 & 1.00 & \\
\hline Very good or excellent & $14 \cdot 3$ & $21 / 147$ & 0.62 & $0.38,1.01$ & 2.4 & $19 / 779$ & 0.74 & $0.37,1.49$ \\
\hline \multicolumn{9}{|l|}{ Social and emotional well-being $†, \ddagger$} \\
\hline High risk of difficulties & $31 \cdot 3$ & $20 / 64$ & 1.00 & & $7 \cdot 4$ & $16 / 217$ & 1.00 & \\
\hline Low risk of difficulties & $21 \cdot 7$ & $43 / 198$ & 0.94 & $0.64,1.37$ & 1.6 & $12 / 748$ & 0.23 & $0.12,0.45$ \\
\hline \multicolumn{9}{|l|}{ BMl category } \\
\hline Overweight or obese & $23 \cdot 3$ & $14 / 60$ & 1.00 & & $2 \cdot 4$ & $8 / 331$ & 1.00 & \\
\hline Normal weight & 28.4 & $38 / 134$ & 0.75 & $0.53,1.06$ & $3 \cdot 2$ & $14 / 441$ & 1.41 & $0.73,2.73$ \\
\hline Underweight & $\leq 25 \cdot 0$ & $\leq 3 / 12$ & 0.54 & $0.16,1 \cdot 81$ & $\leq 50 \cdot 0$ & $\leq 3 / 6$ & $2 \cdot 00$ & $1.01,3.99$ \\
\hline \multicolumn{9}{|l|}{ Family factors } \\
\hline \multicolumn{9}{|l|}{ Carer's general physical health } \\
\hline Poor, fair, or good & $27 \cdot 8$ & 49/176 & 1.00 & & 3.6 & $19 / 529$ & 1.00 & \\
\hline Very good or excellent & $15 \cdot 3$ & $13 / 85$ & 0.66 & $0.34,1.30$ & $2 \cdot 1$ & $9 / 439$ & 0.74 & $0.34,1.60$ \\
\hline Carer's social and emotional we & & & & & & & & \\
\hline High distress & $15 \cdot 7$ & $8 / 51$ & 1.00 & & $7 \cdot 3$ & $14 / 191$ & 1.00 & \\
\hline Low distress & $26 \cdot 3$ & $55 / 209$ & 1.55 & $0.69,3.48$ & 1.8 & $14 / 769$ & 0.27 & $0.15,0.46$ \\
\hline Negative major life events in pas & & & & & & & & \\
\hline $3-9$ & $32 \cdot 3$ & $30 / 93$ & 1.00 & & 3.7 & $11 / 294$ & 1.00 & \\
\hline$<3$ & $19 \cdot 5$ & $33 / 169$ & 0.82 & $0.63,1.07$ & $2 \cdot 5$ & $17 / 673$ & 0.63 & $0.33,1.22$ \\
\hline Carer is partnered $\dagger, \ddagger$ & & & & & & & & \\
\hline No & $20 \cdot 0$ & $22 / 110$ & 1.00 & & $4 \cdot 1$ & $18 / 439$ & 1.00 & \\
\hline Yes & $27 \cdot 0$ & $41 / 152$ & 1.01 & $0.65,1.58$ & 1.9 & $10 / 529$ & 0.41 & $0.22,0.79$ \\
\hline Weekly household income $†$ & & & & & & & & \\
\hline$<\$ A U 600$ & $39 \cdot 7$ & $46 / 116$ & 1.00 & & 4.5 & $15 / 331$ & 1.00 & \\
\hline$\geq \$ A U 600$ & $9 \cdot 6$ & $10 / 104$ & 0.62 & $0.30,1.28$ & $2 \cdot 1$ & $12 / 581$ & 0.51 & $0.29,0.91$ \\
\hline Financial strain†,‡ & & & & & & & & \\
\hline Run out of money & 68.4 & $13 / 19$ & 1.00 & & $6 \cdot 7$ & $8 / 120$ & 1.00 & \\
\hline Just enough money & $27 \cdot 5$ & 28/102 & 0.82 & $0.48,1.40$ & $4 \cdot 3$ & $18 / 419$ & 0.56 & $0.23,1.34$ \\
\hline Can save money & $15 \cdot 8$ & $22 / 139$ & 0.62 & $0.36,1.07$ & 0.5 & $2 / 425$ & 0.07 & $0.02,0.30$ \\
\hline Worries about money in past ye & & & & & & & & \\
\hline Yes & $20 \cdot 5$ & 9/44 & 1.00 & & 4.9 & $14 / 287$ & 1.00 & \\
\hline No & $25 \cdot 1$ & $54 / 215$ & 1.26 & $0.90,1.77$ & $2 \cdot 1$ & $14 / 678$ & 0.36 & $0.19,0.68$ \\
\hline Went without meals in past year & & & & & & & & \\
\hline Yes & $59 \cdot 3$ & $16 / 27$ & 1.00 & & $13 \cdot 3$ & $6 / 45$ & 1.00 & \\
\hline No & $20 \cdot 3$ & $47 / 231$ & 0.56 & $0.36,0.86$ & $2 \cdot 4$ & $22 / 920$ & 0.30 & $0.11,0.77$ \\
\hline Carer's employment status & & & & & & & & \\
\hline Not employed & $25 \cdot 5$ & $41 / 161$ & 1.00 & & $3 \cdot 7$ & $21 / 574$ & 1.00 & \\
\hline Employed part-time & $34 \cdot 3$ & $12 / 35$ & 1.07 & $0.69,1.66$ & $2 \cdot 0$ & $4 / 203$ & 0.63 & $0.21,1.89$ \\
\hline Employed full-time & 14.5 & $9 / 62$ & 0.85 & $0.51,1.44$ & $\leq 1.7$ & $\leq 3 / 172$ & 0.48 & $0.19,1.17$ \\
\hline Carer's highest qualification & & & & & & & & \\
\hline Less than Year 12 & 28.4 & $40 / 141$ & 1.00 & & $3 \cdot 6$ & $18 / 500$ & 1.00 & \\
\hline Year 12 and beyond & $22 \cdot 8$ & $21 / 92$ & $1 \cdot 16$ & $0.83,1.61$ & $2 \cdot 0$ & 8/399 & 0.64 & $0.28,1.45$ \\
\hline Humbugged in past year* $†$ & & & & & & & & \\
\hline Yes & $35 \cdot 6$ & $37 / 104$ & 1.00 & & $6 \cdot 0$ & $14 / 234$ & 1.00 & \\
\hline No & $16 \cdot 6$ & $26 / 157$ & 0.63 & $0.42,0.95$ & 1.9 & $14 / 733$ & 0.39 & $0.16,0.92$ \\
\hline Pressured to support others in th & & & & & & & & \\
\hline Small or big problem & 34.7 & $42 / 121$ & 1.00 & & $7 \cdot 3$ & $13 / 177$ & 1.00 & \\
\hline Not a problem & $14 \cdot 3$ & $18 / 126$ & 0.63 & $0.33,1.22$ & 1.6 & $11 / 700$ & 0.27 & $0.12,0.62$ \\
\hline Feed others who don't live at ho & & & & & & & & \\
\hline A few times a month or more & $29 \cdot 2$ & $42 / 144$ & 1.00 & & $3 \cdot 2$ & $18 / 569$ & 1.00 & \\
\hline Rarely or never & $17 \cdot 1$ & $20 / 117$ & 0.74 & $0.51,1.09$ & 2.5 & $10 / 398$ & 0.91 & $0.46,1.82$ \\
\hline
\end{tabular}




\begin{tabular}{|c|c|c|c|c|c|c|c|c|}
\hline & \multicolumn{4}{|c|}{ Remote/OR } & \multicolumn{4}{|c|}{ Urban/IR } \\
\hline & $\%$ & $n / N$ & PR & $95 \% \mathrm{Cl}$ & $\%$ & $n / N$ & PR & $95 \% \mathrm{Cl}$ \\
\hline \multicolumn{9}{|c|}{ Had evening meal as a family in past week } \\
\hline No & $\leq 15 \cdot 8$ & $\leq 3 / 19$ & 1.00 & & $\leq 7.1$ & $\leq 3 / 42$ & 1.00 & \\
\hline Yes & $25 \cdot 0$ & $60 / 240$ & 0.74 & $0.34,1.62$ & $2 \cdot 8$ & $26 / 924$ & 0.48 & $0.18,1.26$ \\
\hline \multicolumn{9}{|c|}{ Cultural knowledge about bush tucker,$\dagger$} \\
\hline Not important & $12 \cdot 6$ & $12 / 95$ & 1.00 & & 1.8 & $13 / 715$ & 1.00 & \\
\hline Somewhat important & $25 \cdot 0$ & $25 / 100$ & 1.17 & $0.68,2.00$ & $4 \cdot 1$ & $7 / 170$ & 1.77 & $0.78,4.01$ \\
\hline Very important & $38 \cdot 8$ & $26 / 67$ & 1.73 & $0.99,3.01$ & $9 \cdot 8$ & $8 / 82$ & 3.79 & $1.69,8.50$ \\
\hline \multicolumn{9}{|c|}{ Total number of people in household } \\
\hline $2-5$ & $22 \cdot 4$ & $28 / 125$ & 1.00 & & 1.9 & $12 / 625$ & 1.00 & \\
\hline$\geq 6$ & 25.5 & $35 / 137$ & 0.79 & $0.53,1.16$ & 4.7 & $16 / 343$ & 1.80 & $0.71,4.53$ \\
\hline \multicolumn{9}{|c|}{ House felt too crowded in past yeart, $\ddagger$} \\
\hline Yes & $27 \cdot 0$ & $10 / 37$ & 1.00 & & 8.0 & $9 / 113$ & 1.00 & \\
\hline \multirow{2}{*}{\multicolumn{9}{|c|}{ Moved house in past year }} \\
\hline & & & & & & & & \\
\hline Yes & $28 \cdot 2$ & $11 / 39$ & 1.00 & & 3.1 & $6 / 194$ & 1.00 & \\
\hline No & $23 \cdot 1$ & $51 / 221$ & 0.92 & $0.71,1 \cdot 21$ & $2 \cdot 9$ & $22 / 769$ & 1.23 & $0.49,3.05$ \\
\hline \multicolumn{9}{|c|}{ Problem with fridge and/or cooking facilitiest, $\neq$} \\
\hline Yes & $30 \cdot 0$ & $9 / 30$ & 1.00 & & 14.3 & $5 / 35$ & 1.00 & \\
\hline No & $19 \cdot 6$ & $28 / 143$ & 1.09 & $0.73,1.62$ & 2.4 & $16 / 667$ & 0.17 & $0.08,0.36$ \\
\hline \multicolumn{9}{|c|}{ Electrical problems at home* } \\
\hline Yes & 64.7 & $11 / 17$ & 1.00 & & $7 \cdot 7$ & $4 / 52$ & 1.00 & \\
\hline No & 21.4 & $52 / 243$ & 0.69 & $0.51,0.92$ & $2 \cdot 6$ & $24 / 915$ & 0.40 & $0.15,1.07$ \\
\hline \multicolumn{9}{|c|}{ Security problems at home $\dagger$} \\
\hline Yes & $46 \cdot 7$ & $21 / 45$ & 1.00 & & 8.9 & $8 / 90$ & 1.00 & \\
\hline No & $19 \cdot 5$ & $42 / 215$ & 0.76 & $0.50,1.14$ & $2 \cdot 3$ & $20 / 877$ & 0.38 & $0.16,0.88$ \\
\hline \multicolumn{9}{|c|}{ Area-level factors } \\
\hline \multicolumn{9}{|c|}{ Racially-motivated violence ${ }^{*}, t \neq$} \\
\hline Small or big problem & $46 \cdot 7$ & $7 / 15$ & 1.00 & & 5.6 & $9 / 162$ & 1.00 & \\
\hline Not a problem & 23.2 & $53 / 228$ & 0.83 & $0.69,0.99$ & $2 \cdot 1$ & $15 / 729$ & 0.23 & $0.10,0.55$ \\
\hline \multicolumn{9}{|l|}{ Alcohol misuse† } \\
\hline Small or big problem & 27.5 & $53 / 193$ & 1.00 & & 4.9 & $19 / 386$ & 1.00 & \\
\hline Not a problem & 12.5 & $8 / 64$ & 0.56 & $0.28,1.13$ & 1.6 & $9 / 552$ & 0.40 & $0.17,0.93$ \\
\hline \multicolumn{9}{|l|}{ Break-ins or theft } \\
\hline Small or big problem & $27 \cdot 8$ & $35 / 126$ & 1.00 & & $3 \cdot 7$ & $17 / 461$ & 1.00 & \\
\hline Not a problem & 21.4 & $27 / 126$ & 0.96 & $0.69,1.32$ & $2 \cdot 0$ & 9/455 & 0.50 & $0.23,1.08$ \\
\hline \multicolumn{9}{|l|}{ Area-level disadvantage ${ }^{\star}, t$} \\
\hline Least advantaged & $39 \cdot 3$ & $59 / 150$ & 1.00 & & $13 \cdot 8$ & $9 / 65$ & 1.00 & \\
\hline Mid-advantaged & $\leq 2.9$ & $\leq 3 / 102$ & 0.11 & $0.02,0.56$ & 2.6 & $17 / 652$ & 0.21 & $0.06,0.76$ \\
\hline Most advantaged & $\leq 30.0$ & $\leq 3 / 10$ & 0.42 & $0.12,1.45$ & $\leq 1 \cdot 2$ & $\leq 3 / 251$ & 0.06 & $0.01,0.34$ \\
\hline \multicolumn{9}{|l|}{ Remoteness } \\
\hline None & - & - & - & - & $2 \cdot 0$ & 7/348 & 1.00 & \\
\hline Low & - & - & - & - & $3 \cdot 4$ & $21 / 620$ & 1.64 & $0.55,4.90$ \\
\hline Moderate & $17 \cdot 7$ & 28/158 & 1.00 & & - & - & - & - \\
\hline High/extreme & $33 \cdot 7$ & $35 / 104$ & 2.04 & $0.63,6.62$ & - & - & - & - \\
\hline
\end{tabular}

Remote/OR, remote/outer regional; urban/IR, urban/inner regional; PR, prevalence ratio.

All models are adjusted for age group, sex and remoteness, and take into account the clustered nature of the data set. $P_{\text {interaction }}<0.05$ indicates relationship between exposure and accessibility barriers is significantly different in urban/IR $v$. remote/OR areas.

*Variable significantly associated with accessibility barriers in remote/OR areas ( $P$ for Wald test $<0.05)$.

†Variable significantly associated with accessibility barriers in urban/IR areas $(P$ for Wald test $<0.05)$.

¥Significant difference in the relationship of the exposure to accessibility barriers between remote/OR and urban/IR carers $\left(P_{\text {interaction }}<0.05\right)$.

§Inadequate data to assess $P_{\text {interaction. }}$.

children had good physical health and social and emotional well-being; the prevalence of dislike also varied by the employment status of the carer. Carers were significantly less likely to report dislike as a barrier if they lived in communities where there was no problem with alcohol use $(32 \cdot 7 v$. 36.1\%; PR=0.9, $95 \%$ CI $0 \cdot 8,1 \cdot 0)$.

We did not observe significant variation in the prevalence of dislike by remoteness, or observe material changes in the relationship between exposures and dislike after additional adjustment for remoteness; thus, there was no indication for separate examination of these relationships in the remote/OR and urban/IR samples.

\section{Contextualisation}

Accessibility barriers

Key informants provided insight into the meaning of carers' reported barriers to children's fruit and vegetable consumption and their relationship to child, family and community factors. Key informants explained that in 
Table 4 Factors associated with children's dislike of fruit and vegetable intake, among children whose carers who did not report accessibility barriers, in the Australian Longitudinal Study of Indigenous Children (LSIC), Wave 6, 2013

\begin{tabular}{|c|c|c|c|c|c|c|}
\hline & \multirow[b]{2}{*}{$\%$} & \multirow[b]{2}{*}{$n / N$} & \multicolumn{2}{|c|}{ Adjusted for age and sex } & \multicolumn{2}{|c|}{$\begin{array}{l}\text { Adjusted for age, sex anc } \\
\text { remoteness }\end{array}$} \\
\hline & & & PR & $95 \% \mathrm{Cl}$ & PR & $95 \% \mathrm{Cl}$ \\
\hline Total & $34 \cdot 2$ & $390 / 1139$ & - & - & - & - \\
\hline \multicolumn{7}{|l|}{ Child factors } \\
\hline \multicolumn{7}{|l|}{ Sex } \\
\hline Male & 33.6 & $192 / 571$ & 1.00 & & 1.00 & \\
\hline Female & 34.9 & $198 / 568$ & 1.04 & $0.86,1.25$ & 1.04 & $0.86,1.25$ \\
\hline \multicolumn{7}{|l|}{ Age group } \\
\hline $4-5$ years & 33.7 & $85 / 252$ & 1.00 & & 1.00 & \\
\hline $6-7$ years & $32 \cdot 7$ & $141 / 431$ & 0.97 & $0.80,1.17$ & 0.98 & $0.81,1.18$ \\
\hline $8-10$ years & $36 \cdot 0$ & $164 / 456$ & 1.07 & $0.88,1.29$ & 1.07 & $0.88,1.29$ \\
\hline \multicolumn{7}{|l|}{ Indigenous identification } \\
\hline Aboriginal & $35 \cdot 0$ & $346 / 988$ & 1.00 & & 1.00 & \\
\hline Torres Strait Islander & $27 \cdot 4$ & $23 / 84$ & 0.78 & $0.58,1.04$ & 0.83 & $0.59,1.16$ \\
\hline Both & 31.3 & $21 / 67$ & 0.91 & $0.65,1.27$ & 0.92 & $0.65,1.30$ \\
\hline \multicolumn{7}{|l|}{ General physical health*, $\dagger$} \\
\hline Poor, fair, or good & $40 \cdot 7$ & $103 / 253$ & 1.00 & & 1.00 & \\
\hline Very good or excellent & $32 \cdot 4$ & $287 / 886$ & 0.80 & $0.68,0.94$ & 0.77 & $0.65,0.92$ \\
\hline \multicolumn{7}{|l|}{ Social and emotional well-being ${ }^{\star}, \dagger$} \\
\hline High risk of difficulties & $39 \cdot 2$ & $96 / 245$ & 1.00 & & 1.00 & \\
\hline \multirow{2}{*}{\multicolumn{7}{|c|}{ BMI category }} \\
\hline & & & & & & \\
\hline Overweight or obese & 35.5 & $131 / 369$ & 1.00 & & 1.00 & \\
\hline Normal weight & $35 \cdot 2$ & $184 / 523$ & 1.00 & $0.85,1.17$ & 1.01 & $0.86,1.19$ \\
\hline Underweight & $\leq 20 \cdot 0$ & $\leq 3 / 15$ & $0 \cdot 18$ & $0.03,1.10$ & 0.21 & $0.03,1.26$ \\
\hline \multicolumn{7}{|l|}{ Family factors } \\
\hline Carer's general physical health & & & & & & \\
\hline Poor, fair, or good & 33.9 & 216/637 & 1.00 & & 1.00 & \\
\hline Very good or excellent & 34.7 & $174 / 502$ & 1.03 & $0.85,1.24$ & 1.02 & $0.84,1.23$ \\
\hline Carer's social and emotional we & & & & & & \\
\hline High distress & 38.2 & $84 / 220$ & 1.00 & & 1.00 & \\
\hline Low distress & 33.3 & $303 / 909$ & 0.87 & $0.73,1.03$ & 0.87 & $0.73,1.03$ \\
\hline Negative major life events in pas & & & & & & \\
\hline $3-9$ & 33.7 & 267/792 & 1.00 & & 1.00 & \\
\hline$<3$ & $35 \cdot 3$ & $122 / 346$ & 0.96 & $0.81,1.14$ & 0.96 & $0.81,1 \cdot 13$ \\
\hline Carer is partnered & & & & & & \\
\hline No & $31 \cdot 2$ & $159 / 509$ & 1.00 & & 1.00 & \\
\hline Yes & $36 \cdot 7$ & $231 / 630$ & 1.18 & $0.98,1.42$ & 1.18 & $0.98,1.42$ \\
\hline Weekly household income & & & & & & \\
\hline$<\$ A \cup 600$ & 33.4 & $129 / 386$ & 1.00 & & 1.00 & \\
\hline$\geq \$ A U 600$ & 35.6 & $236 / 663$ & 1.06 & $0.86,1.31$ & 1.05 & $0.85,1.30$ \\
\hline Financial strain & & & & & & \\
\hline Run out of money & 34.7 & $41 / 118$ & 1.00 & & 1.00 & \\
\hline Just enough money & $36 \cdot 6$ & $174 / 475$ & 1.06 & $0.85,1.31$ & 1.08 & $0.87,1.34$ \\
\hline Can save money & $31 \cdot 7$ & $171 / 540$ & 0.92 & $0.73,1.15$ & 0.95 & $0.75,1.19$ \\
\hline Worries about money in past ye & & & & & & \\
\hline Yes & $31 \cdot 2$ & $96 / 308$ & 1.00 & & 1.00 & \\
\hline No & 35.2 & $290 / 825$ & 1.13 & $0.94,1.36$ & 1.15 & $0.96,1.38$ \\
\hline Went without meals in past year & & & & & & \\
\hline Yes & 38.0 & $19 / 50$ & 1.00 & & 1.00 & \\
\hline No & 33.9 & $367 / 1082$ & 0.88 & $0.63,1.25$ & 0.87 & $0.61,1.25$ \\
\hline Carer's employment status ${ }^{\star}, \dagger$ & & & & & & \\
\hline Not employed & $30 \cdot 8$ & $207 / 673$ & 1.00 & & 1.00 & \\
\hline Employed part-time & 41.9 & 93/222 & 1.36 & $1.12,1.64$ & 1.34 & $1.11,1.62$ \\
\hline Employed full-time & $35 \cdot 1$ & $78 / 222$ & 1.14 & $0.90,1.44$ & 1.16 & $0.91,1.46$ \\
\hline Carer's highest qualification & & & & & & \\
\hline Less than Year 12 & 33.1 & $193 / 583$ & 1.00 & & 1.00 & \\
\hline Year 12 and beyond & $37 \cdot 2$ & $172 / 462$ & $1 \cdot 12$ & $0.94,1.33$ & $1 \cdot 12$ & $0.93,1.34$ \\
\hline Humbugged in past year & & & & & & \\
\hline Yes & $32 \cdot 4$ & $93 / 287$ & 1.00 & & 1.00 & \\
\hline No & 34.7 & $295 / 850$ & 1.07 & $0.90,1.27$ & 1.05 & $0.89,1.24$ \\
\hline Pressured to support others in th & & & & & & \\
\hline Small or big problem & 33.3 & $81 / 243$ & 1.00 & & 1.00 & \\
\hline Not a problem & $34 \cdot 0$ & $271 / 797$ & 1.02 & $0.80,1.29$ & 0.98 & $0.78,1.24$ \\
\hline Feed others who don't live at ho & & & & & & \\
\hline A few times a month or more & $36 \cdot 1$ & $236 / 653$ & 1.00 & & 1.00 & \\
\hline Rarely or never & 31.8 & $154 / 485$ & 0.88 & $0.74,1.04$ & 0.89 & $0.75,1.04$ \\
\hline
\end{tabular}




\begin{tabular}{|c|c|c|c|c|c|c|}
\hline & \multirow[b]{2}{*}{$\%$} & \multirow[b]{2}{*}{$n / N$} & \multicolumn{2}{|c|}{ Adjusted for age and sex } & \multicolumn{2}{|c|}{$\begin{array}{l}\text { Adjusted for age, sex anc } \\
\text { remoteness }\end{array}$} \\
\hline & & & PR & $95 \% \mathrm{Cl}$ & PR & $95 \% \mathrm{Cl}$ \\
\hline \multicolumn{7}{|c|}{ Had evening meal as a family in past week } \\
\hline No & $39 \cdot 3$ & $22 / 56$ & 1.00 & & 1.00 & \\
\hline Yes & 33.9 & $365 / 1078$ & 0.86 & $0.67,1.11$ & 0.84 & $0.65,1.09$ \\
\hline \multicolumn{7}{|c|}{ Cultural knowledge about bush tucker* } \\
\hline Not important & $36 \cdot 8$ & $289 / 785$ & 1.00 & & 1.00 & \\
\hline Somewhat important & $30 \cdot 7$ & $73 / 238$ & 0.83 & $0.66,1.06$ & 0.85 & $0.66,1.10$ \\
\hline Very important & 23.5 & $27 / 115$ & 0.64 & $0.45,0.91$ & 0.66 & $0.45,0.95$ \\
\hline \multicolumn{7}{|c|}{ Total number of people in household } \\
\hline $2-5$ & $35 \cdot 1$ & $249 / 710$ & 1.00 & & 1.00 & \\
\hline$\geq 6$ & 32.9 & $141 / 429$ & 0.94 & $0.80,1.09$ & 0.95 & $0.82,1.11$ \\
\hline \multicolumn{7}{|c|}{ House felt too crowded in past year } \\
\hline Yes & 39.7 & $52 / 131$ & 1.00 & & 1.00 & \\
\hline No & 33.3 & $334 / 1002$ & 0.84 & $0.67,1.06$ & 0.84 & $0.67,1.04$ \\
\hline \multicolumn{7}{|l|}{ Moved house in past year } \\
\hline Yes & $30 \cdot 1$ & $65 / 216$ & 1.00 & & 1.00 & \\
\hline No & $35 \cdot 0$ & $321 / 917$ & $1 \cdot 16$ & $0.93,1.44$ & 1.17 & $0.94,1.46$ \\
\hline \multicolumn{7}{|c|}{ Problem with fridge and/or cooking facilities } \\
\hline Yes & $35 \cdot 3$ & $18 / 51$ & 1.00 & & 1.00 & \\
\hline No & $36 \cdot 0$ & $276 / 766$ & 1.02 & $0.68,1.52$ & 0.98 & $0.65,1.48$ \\
\hline \multicolumn{7}{|c|}{ Electrical problems at home } \\
\hline Yes & $35 \cdot 2$ & $19 / 54$ & 1.00 & & 1.00 & \\
\hline No & $34 \cdot 0$ & $368 / 1082$ & 0.97 & $0.66,1.42$ & 0.98 & $0.67,1.44$ \\
\hline \multicolumn{7}{|l|}{ Security problems at home } \\
\hline Yes & $37 \cdot 7$ & $40 / 106$ & 1.00 & & 1.00 & \\
\hline No & 33.7 & $347 / 1030$ & 0.89 & $0.69,1 \cdot 17$ & 0.88 & $0.68,1.15$ \\
\hline \multicolumn{7}{|c|}{ Area-level factors } \\
\hline \multicolumn{7}{|c|}{ Racially motivated violence } \\
\hline Small or big problem & $36 \cdot 0$ & $58 / 161$ & 1.00 & & 1.00 & \\
\hline Not a problem & 33.6 & $299 / 889$ & 0.94 & $0.70,1.25$ & 0.97 & $0.72,1.30$ \\
\hline \multicolumn{7}{|l|}{ Alcohol misuse $†$} \\
\hline Small or big problem & $36 \cdot 1$ & $183 / 507$ & 1.00 & & 1.00 & \\
\hline Not a problem & $32 \cdot 7$ & $196 / 599$ & 0.91 & $0.78,1.05$ & 0.86 & $0.75,1.00$ \\
\hline \multicolumn{7}{|l|}{ Break-ins or theft } \\
\hline Small or big problem & $36 \cdot 3$ & $194 / 535$ & 1.00 & & 1.00 & \\
\hline Not a problem & 31.4 & $171 / 545$ & 0.86 & $0.73,1.02$ & 0.87 & $0.74,1.02$ \\
\hline \multicolumn{7}{|l|}{ Area-level disadvantage } \\
\hline Least advantaged & $30 \cdot 6$ & $45 / 147$ & 1.00 & & 1.00 & \\
\hline Mid-advantaged & 33.5 & $246 / 734$ & 1.09 & $0.82,1.46$ & 1.00 & $0.76,1.33$ \\
\hline Most advantaged & 38.4 & $99 / 258$ & 1.25 & $0.92,1.72$ & $1 \cdot 18$ & $0.84,1.65$ \\
\hline \multicolumn{7}{|l|}{ Remoteness } \\
\hline None & $35 \cdot 2$ & $120 / 341$ & 1.00 & - & - & \\
\hline Low & $35 \cdot 6$ & $213 / 599$ & 1.01 & $0.82,1.24$ & - & - \\
\hline Moderate & 28.5 & $37 / 130$ & 0.82 & $0.58,1.14$ & _ & - \\
\hline High/extreme & $29 \cdot 0$ & $20 / 69$ & 0.81 & $0.62,1.06$ & - & - \\
\hline
\end{tabular}

All models take into account the clustered nature of the data set.

*Variable significantly associated with dislike in model adjusted for age group and sex ( $P$ for Wald test $<0.05)$.

†Variable significantly associated with dislike in model adjusted for age group, sex and remoteness $(P$ for Wald test $<0.05)$.

remote/OR settings, low incomes, high food prices and pressures to support others compound to prevent carers from providing their children with fruit and vegetables despite awareness of the nutritional benefits:

'A lot of people in the sort of remote communities are on benefits. And if you have got to feed a couple of kids ... and you have to buy all of this fruit and veg, whereas you can have a couple packages of chips, or takeaway well, what are you going to do? ... Even though they may know it's [fruit and veg] really good for them.'

Key informants explained how demand sharing influenced carers' food purchasing behaviours, for example, discouraging carers from buying certain types of food:

'Because if your child walks outside with watermelon, then you've got fifty kids all of a sudden knocking on your door.'

Given the existing barriers to purchasing healthy foods, key informants explained that health promotion efforts to increase children's desire to eat fruit and vegetables have the unintended consequence of disempowering parents:

'Because the kids do get, "You have to do this, have to do this", go home and hassle Mum. "We need to do this, we need to do that". And they're [parents 
are] already under lots of pressure, stress. So, I think if they do those sorts of things [nutrition education], they've got to do something about the supply.'

Another key informant explained how families struggled to achieve the 'Australian dream' of providing a healthy diet for their children:

'But what can you do? There is the pressure of education - you've got to send these kids to school, got to give them healthy lunches. Parents spend but how far that $\$ 500$ takes them; it's not far. There is this health education; trying to live the Australian dream but you can't.'

Key informants also described the limited availability and poor quality of fresh produce in remote/OR settings. For example, one key informant depicted the quality of fresh produce in remote/OR areas by asking, 'Have you ever eaten frozen lettuce?

Interviewers also commented that the competing affordability and availability of fast food was a barrier to the consumption of healthier foods; a key informant from an urban/IR setting explained that:

'When somebody told me that veggies were too expensive back in my area, it would have been because Macca's [McDonald's] costs a lot less ... it's just that there is a cheaper alternative.'

Carers' time scarcity was also considered an important barrier to nutrition, favouring quicker meal options such as takeaway.

\section{Dislike}

Key informants explained that children's dislike of vegetables was a common problem, although many children were happy to eat fruit. One stated:

'I came across this same complaint. That was, you cook it, and you prepare it, and they just don't eat it.'

Key informants identified children's lack of familiarity with some types of vegetables as an important contributor to their refusal to eat them:

'It's like introducing it to them ... You give them a bowl of salad and some veggies, and they freak out; they just eat the meat and rice and they push the veggies aside. We tell them, "It's good for you" but it sort of, it takes time to adjust.'

Key informants commented that the expense of throwing away' was a barrier to purchasing vegetables when there was a risk that children would refuse to eat them. They also explained that carers wanted to provide food that the child wanted to eat; carers' food provision was more about 'pleasing' the child 'than it is about what they're feeding them at this stage'. The ubiquity of alternatives such as lollies and fast food, particularly in more urban areas, was considered to contribute to children's picky eating and refusal to eat vegetables.

\section{Discussion}

In this diverse national sample, almost half of carers reported barriers to their children's nutrition. Barriers to fruit intake were less commonly reported than barriers to vegetable intake, but both are considered important nutritionally. Multiple barriers restrict Indigenous children's consumption of fruit and vegetables. The most commonly reported barrier was children's dislike of fruit and vegetables. Problems accessing fruit and vegetables were common among carers living in remote/OR settings and among disadvantaged carers living in urban/IR settings; the cost, availability and quality of fruit and vegetables were substantial barriers to access. Child and carer well-being, financial security, suitable housing and community cohesion promoted access to fruit and vegetables.

\section{Accessibility barriers}

In this sample, carers were over ten times more likely to face problems accessing fruit and vegetables for their children if they lived in very remote areas compared with large cities. This is consistent with the increased price of fresh food in remote areas ${ }^{(18)}$ and the limited availability and poor quality of fresh foods, particularly after extended transportation $^{(17)}$. These characteristics of the remote/OR food environment may explain why we observed few factors significantly associated with accessibility barriers within this group: where the environment itself creates substantial barriers to access, individual characteristics may become less important.

Within the urban/IR group, disadvantaged carers faced a tenfold increase in the relative risk of accessibility barriers compared with advantaged carers. Key informants described how the affordability and availability of fast-food outlets in urban/IR areas negatively influenced children's consumption of fruit and vegetables. These findings are consistent with the literature ${ }^{(26,54,55)}$ and the increased availability of fast-food outlets in disadvantaged $v$. advantaged urban settings ${ }^{(56,57)}$. Additionally, some literature has also documented reduced accessibility of healthy foods in disadvantaged areas of Australia ${ }^{(58)}$, although findings are mixed ${ }^{(15,57,59,60)}$. Thus, for carers living in both remote/OR and disadvantaged urban/IR areas, the food environment constrained their ability to provide their child with a healthy diet, despite their nutritional awareness.

The present work provides quantitative evidence that multiple domains of financial security, including reported income, financial strain and worries about money, relate to carers' ability to access fruit and vegetables for their children. These findings are consistent with evidenced socio-economic gradients in dietary intake; healthy diets 
tend to be more expensive than unhealthy diets ${ }^{(22,61)}$ and the literature describes an increased reliance on energydense foods (rather than nutrient-dense foods such as fruit and vegetables) by families with limited financial resources and time ${ }^{(19,62,63)}$.

Our findings provide quantitative evidence on the link between resource sharing and carers' ability to purchase healthy foods. Consistent with previous qualitative findings $^{(12,17,21,27,64)}$, our key informants explained that demand sharing encouraged the purchasing of energy-dense foods and discouraged the purchasing of sought-after foods that others are likely to request. Our findings also support the importance of adequate housing - in terms of crowding and household infrastructure - in promoting children's nutrition $^{(9,21,65,66)}$. Many Indigenous households contain extended family members rather than being restricted to the nuclear family, due to cultural differences in family structures and obligations to care for family. Lower socioeconomic status and limited availability of quality housing (particularly in remote areas) further contribute to large numbers of household members, which is linked to the breakdown of housing infrastructure ${ }^{(67,68)}$

Our study identified a relationship between access to fruit and vegetables and the social and emotional well-being of children and their carers. Key informants indicated that carers might experience distress or feel disempowered if they are unable to oblige their children's requests for fruit and vegetables. These relationships may also be partially mediated by children's and carer's exposure to stressors and disadvantage. In both remote/OR and urban/IR settings, carers were more likely to report accessibility barriers if they considered it very important to pass on cultural knowledge about bush tucker. This might reflect that carers who value bush tucker reported barriers to accessing traditional fruit and vegetables or, alternatively, that carers who perceive accessibility barriers want to teach their children about bush tucker in order to supplement their diet.

We also observed a relationship between measures of community functioning (racially motivated violence and alcohol misuse) and carers' ability to access fruit and vegetables for their children, providing evidence that community characteristics relate to children's health ${ }^{(39)}$. The link between community-level racism and access to nutrition is consistent with wider literature linking racism to reduced access to resources required for health ${ }^{(69,70)}$. In communities where racism is perceived to be a problem, Indigenous people may be reluctant to go to food outlets; a qualitative study identified that some urban Indigenous people experiencing racism within their neighbourhood adopt an 'avoidance strategy' ${ }^{,(71)}$. The relationship between racism and accessibility barriers might be partially mediated by social and emotional well-being of the child and carer ${ }^{(69,72,73)}$ or by area-level disadvantage. Carers were also more likely to report barriers to accessing fruit and vegetables for their children if they perceived a problem with alcohol use in their community; carers may avoid shopping at food outlets where they perceive they may encounter alcohol-related issues, such as being asked for money to purchase alcohol.

\section{Differences in remote/outer regional v. urban/inner regional areas}

We generally observed consistent patterns in the associations between exposures and accessibility barriers in remote/OR and in urban/IR environments. However, there were some cases in which these relationships were statistically different. Some of the significant interactions observed might result from the high base prevalence of accessibility barriers in the remote/OR sample, which puts a ceiling on the possible magnitude of the relative risks within this group. This lack of potential for variation and the reduced sample size in the remote/OR sample limit the power to detect significant differences within the group. Although the relative risks observed within the remote/OR sample are often smaller in magnitude than those observed in the urban/IR sample, they are still associated with a large absolute difference in the proportion of carers experiencing the outcome (e.g. for financial strain and racially motivated violence). In addition, it is important to consider that some significant interactions could have resulted from multiple testing.

\section{Dislike}

Where fruit and vegetables were accessible, children's dislike was a substantial barrier to intake, indicating that it is important to consider multiple barriers when designing interventions to promote children's fruit and vegetable consumption. Further, factors associated with dislike did not appear to be congruent with factors associated with accessibility barriers, suggesting that different population groups may face different barriers.

One-third of carers reported that children's dislike was a barrier, with carers predominantly reporting an issue with dislike of vegetables, rather than fruit. These findings are consistent with comments by key informants, international literature on 'picky eating, ${ }^{(74)}$ and a qualitative study on healthy eating among Aboriginal families in urban Victoria $^{(19)}$. There is no accepted definition of picky eating, but it generally encompasses discomfort in eating familiar foods and/or unfamiliar foods ${ }^{(75)}$, and is considered to be associated with poorer diet quality, particularly an avoidance of vegetables, and increased intake of energy-dense snacks and sweets ${ }^{(74)}$. Internationally, the estimated prevalence of picky eating ranges from 6 to $50 \%$, with the peak prevalence among children aged 3 years (younger than our sample).

There is limited evidence on factors associated with picky eating. Research from the UK suggests a relationship between picky eating and socio-economic status ${ }^{(74)}$, but we did not observe a relationship between picky eating (dislike) and measures of socio-economic status in our sample, with the exception of carers' employment status. This might have resulted from our restriction of the sample 
to carers who did not face accessibility problems, which removed some of the most disadvantaged families from the sample.

Our findings support research on the importance of familiarity and habit in shaping food choice ${ }^{(17)}$; key informants identified children's lack of familiarity as an important contributor to their refusal to eat certain vegetables. The preference for familiar foods (such as those high in sugar and processed flour such as white bread) has been considered a lasting legacy of the colonial history that dramatically altered Indigenous food practices and preferences $^{(12,13,21,26,76)}$.

The predominance of children's dislike as a barrier to fruit and vegetable consumption is also consistent with the literature on traditional views of child autonomy and children's ability to make their own choices ${ }^{(17,64,77-79)}$. This was supported by our key informants, who described the importance carers place on children's own food preferences. Forcing children to eat fruit and vegetables conflicts with this cultural value; instead, carers are limited to influencing children's food choice by encouraging them to consider healthy choices ${ }^{(13,37,77,78,80-82)}$.

Carers were less likely to report dislike for children with good physical health and social and emotional well-being, consistent with literature on the association between picky eating and physical, emotional and social impairment ${ }^{(83)}$. A strategy for overcoming children's picky eating is to repeatedly expose (at least ten times) the child to the disliked food ${ }^{(74,84)}$. This approach is not feasible when the relevant foods are not readily available or are of poor quality, or when resources are scarce and there is concern about food wastage and hunger ${ }^{(19,20)}$, as mentioned by the key informants. Thus, although we have examined them separately, barriers related to dislike and to accessibility are likely to be entangled.

\section{Limitations}

The current study relies predominantly on carer-reported data and findings should be interpreted as such. Our outcome reflects carers' perceived barriers to their children's nutrition, rather than actual barriers; however, previous research has demonstrated that perceived barriers are significantly correlated with intake ${ }^{(85,86)}$. We have validated that carers' perception of barriers was closely tied to reported low intake by children, and that there was no material difference between the relationship of factors to low intake and to the perception of barriers. Further, our qualitative findings supported our quantitative findings, although we acknowledge that these qualitative findings were also based on the participants' perceptions of these issues. A limitation of our outcome variable is that it would not serve as an indicator of a child's nutrition status in cases where the child's intake of fruit/vegetables exceeded recommended intake but the carer reported that they want their child to eat more, or in cases where the child's intake of fruit/vegetables did not meet recommended intake but the carer reported that they do not want their child to eat more.

We recognise that there may be differences in the types of barriers reported, and the associated risk factors, in relation to fruit intake $v$. vegetable intake. For example, dislike is understood to be a more common barrier to vegetable intake than to fruit intake ${ }^{(75)}$. We have examined barriers to fruit and vegetable intake combined because fruit and vegetables play a similar nutritional role, and accessibility barriers for fruit and for vegetables are generally similar, as well as for pragmatic reasons.

The LSIC is not designed to be representative of the Australian Indigenous population; however, the LSIC data offer diversity in geography and environmental conditions and are well-suited for internal comparisons. Our study is based on cross-sectional data, so we cannot make inferences about causality. The potential biases arising from missing data should be minimal given that over $99 \%$ ( $n$ 1230/1239) of carers participating in the survey provided data on the outcome and the majority of exposure variables had less than $1 \%$ of data missing.

Grouping environments into discrete categories of remoteness is likely to have the effect of combining individuals living in areas across a range of remoteness, but the use of these categories is pragmatic and can define groups with similarities in life circumstances, such as the dominant social and cultural setting ${ }^{(87)}$.

\section{Conclusions}

To our knowledge, the present study is the first large-scale investigation of barriers to Indigenous Australian children's nutrition across heterogeneous environments. It provides quantitative evidence that a broad range of social, cultural and environmental factors impact nutrition. Disadvantaged Indigenous families in urban and inner regional settings, as well as those living in remote and outer regional areas, face substantial barriers to accessing fruit and vegetables. Where fruit and vegetables were accessible, dislike of vegetables was a common barrier.

Approaches to improve equity in nutrition in Australia need to address these barriers, through a combination of policy to improve the food environment in remote/OR and disadvantaged urban/IR settings and culturally relevant programmes to promote underlying determinants including financial security, housing and community cohesion $^{(22)}$. Programmes and policies to promote nutrition should draw on the strengths of Indigenous families and communities, and must be conducted in partnership with Indigenous communities and individuals ${ }^{(24,88)}$.

\section{Acknowledgements}

Acknowledgements: The authors acknowledge all the traditional custodians of the lands and pay respect to 
Elders past, present and future. They acknowledge the generosity of the Aboriginal and Torres Strait Islander families who participated in the study, and the Elders of their communities. This paper uses unit record data from the Longitudinal Study of Indigenous Children (LSIC). LSIC was initiated and is funded and managed by the Australian Government Department of Social Services (DSS). The findings and views reported in this paper, however, are those of the authors and should not be attributed to DSS or the Indigenous people and their communities involved in the study. The authors would like to thank the LSIC Research Administration Officers for sharing their views during the focus group discussion and LSIC staff at the DSS (particularly Fiona Skelton) for their support and assistance. They would also like to acknowledge staff at Apunipima Cape York Council (particularly Cara Polson) for providing guidance. Financial support: This work was supported by the Australian National University (K.A.T., University Research Scholarship); the National Health and Medical Research Council of Australia (E.B., grant number 1042717), (R.L., grant 1088366), (M.P., grant number 9100001 - The Australian Prevention Partnership Centre). Conflict of interest: None. Authorship: K.A.T., E.B. and C.B. conceptualised the study. K.A.T., E.B., T.N. and T.D. contributed to the design of quantitative analyses; C.B. assisted with the planning and analysis of the qualitative component. K.A.T. conducted all quantitative analyses, and conducted and transcribed the focus group. R.L. and M.P. provided critical assistance with the interpretation of findings and the framing of the manuscript. K.A.T. drafted the manuscript; all authors provided feedback.

\section{Supplementary material}

To view supplementary material for this article, please visit https://doi.org/10.1017/S1368980016003013

\section{References}

1. Institute for Health Metrics and Evaluation (2013) Global Burden of Disease Profile: Australia. Seattle, WA: IHME.

2. Vos DT (2007) The Burden of Disease and Injury in Aboriginal and Torres Strait Islander Peoples 2003. Herston, QLD: Centre for Burden of Disease and CostEffectiveness, School of Population Health, University of Queensland.

3. Australian Government National Health and Medical Research Council (2013) Australian Dietary Guidelines: Providing the Scientific Evidence for Healthier Australian Diets. Canberra, ACT: Commonwealth of Australia.

4. Australian Bureau of Statistics (2014) 4727.0.55.006 Australian Aboriginal and Torres Strait Islander Health Survey: Updated Results, 2012-13. http://www.abs.gov.au/ AUSSTATS/abs@.nsf/mf/4727.0.55.006 (accessed April 2016).

5. Australian Bureau of Statistics (2012) 4364.0.55.001 Australian Health Survey: Updated results, 2011-2012. http://www.abs.gov.au/ausstats/abs@.nsf/mf/4364.0.55.003 (accessed April 2016).

6. Closing the Gap Clearinghouse (2012) Healthy Lifestyle Programs for Physical Activity and Nutrition. Canberra,
ACT and Melbourne, VIC: Australian Institute of Health and Welfare and Australian Institute of Family Studies.

7. Pascoe B (2009) The Little Red Yellow Black Book: An Introduction to Indigenous Australia, 3rd ed. Canberra, ACT: Australian Institute of Aboriginal and Torres Strait Islander Studies, Aboriginal Studies Press.

8. Australian Bureau of Statistics (2013) 3238.0.55.001 - Estimates of Aboriginal and Torres Strait Islander Australians, June 2011. http://www.abs.gov.au/ausstats/abs@.nsf/mf/3238.0.55.001 (accessed August 2016).

9. Browne J, Laurence S \& Thorpe S (2009) Acting on food insecurity in urban Aboriginal and Torres Strait Islander communities: policy and practice interventions to improve local access and supply of nutritious food. Australian Indigenous HealthInfoNet. http://www.healthinfonet.ecu.edu. $\mathrm{au} /$ health-risks/nutrition/reviews/other-reviews (accessed August 2016).

10. Australian Institute of Health and Welfare (2014) Australia's Health 2014. Australia's Health Series no. 14. Catalogue no. AUS 178. Canberra, ACT: AIHW.

11. Biddle N \& Markham MF (2013) Socioeconomic Outcomes. CAEPR Indigenous Population Project 2011 Census Papers no. 13/2013. Canberra, ACT: Centre for Aboriginal Economic Policy Research.

12. Thompson SJ, Gifford SM \& Thorpe L (2000) The social and cultural context of risk and prevention: food and physical activity in an urban Aboriginal community. Health Educ Behav 27, 725-743.

13. Colles SL, Maypilama E \& Brimblecombe J (2014) Food, food choice and nutrition promotion in a remote Australian Aboriginal community. Aust J Prim Health 20, 365-372.

14. Lee A, Baker P, Stanton R et al. (2013) Scoping Study to Inform Development of the National Nutrition Policy for Australia. Canberra, ACT: Australian Government Department of Health.

15. Zarnowiecki D, Ball K, Parletta N et al. (2014) Describing socioeconomic gradients in children's diets - does the socioeconomic indicator used matter? Int J Behav Nutr Phys Act 11, 44.

16. Harrison MS, Coyne T, Lee AJ et al. (2007) The increasing cost of the basic foods required to promote health in Queensland. Med J Aust 186, 9-14.

17. Henryks J \& Brimblecombe J (2016) Mapping point-ofpurchase influencers of food choice in Australian remote Indigenous communities. SAGE Open 6, 2158244016629183.

18. Ferguson M, O'Dea K, Chatfield M et al. (2015) The comparative cost of food and beverages at remote Indigenous communities, Northern Territory, Australia. Aust NZJ Public Health 40, Suppl. 1, S21-S26.

19. Adams K, Burns C, Liebzeit A et al. (2012) Use of participatory research and photo-voice to support urban Aboriginal healthy eating. Health Soc Care Community 20, 497-505.

20. Foley W (2010) Family food work: lessons learned from urban Aboriginal women about nutrition promotion. Aust J Prim Health 16, 268-274.

21. Saethre E (2011) Demand sharing, nutrition and Warlpiri Health: the social and economic strategies of food choice. In Ethnography and the Production of Anthropological Knowledge: Essays in Honour of Nicolas Peterson, pp. 175186 [Y Musharbash and M Barber, editors]. Canberra, ACT: ANU E Press.

22. Peeters A \& Blake MR (2016) Socioeconomic inequalities in diet quality: from identifying the problem to implementing solutions. Curr Nutr Rep 8, 150-159.

23. Hunt J, Bond C \& Brough M (2004) Strong in the city: towards a strength-based approach in Indigenous health promotion. Health Promot J Aust 15, 215-220.

24. Foley W \& Schubert L (2013) Applying strengths-based approaches to nutrition research and interventions in Indigenous Australian communities. J Crit Diet 1, 15-25. 
25. Altman J (2011) A genealogy of 'demand sharing': from pure anthropology to public policy. In Ethnography and the Production of Anthropological Knowledge: Essays in Honour of Nicolas Peterson, pp. 187-200 [Y Musharbash and $\mathrm{M}$ Barber, editors]. Canberra, ACT: ANU E Press.

26. Foley W (2005) Tradition and change in urban indigenous food practices. Postcolonial Stud 8, 25-44.

27. Waterworth P, Rosenberg M, Braham R et al. (2014) The effect of social support on the health of Indigenous Australians in a metropolitan community. Soc Sci Med 119, 139-146.

28. Gerrard G (1989) Everyone will be jealous for that Mutika. Mankind 19, 95-111.

29. Kuhnlein HV, Erasmus B, Spigelski D et al. (2013) Indigenous Peoples' Food Systems and Well-Being: Interventions and Policies for Healthy Communities. Rome: FAO.

30. Luke JN, Ritte R, O'Dea K et al. (2016) Nutritional predictors of successful chronic disease prevention for a community cohort in Central Australia. Public Health Nutr 19, 2478-2483.

31. Gracey M (2000) Historical, cultural, political, and social influences on dietary patterns and nutrition in Australian Aboriginal children. Am J Clin Nutr 72, 5 Suppl. 1361S-1367S

32. Lee A (1996) The transition of Australian Aboriginal diet and nutritional health. World Rev Nutr Diet 79, 1-52.

33. Saethre E (2005) Nutrition, economics, and food distribution in an Australian Aboriginal community. Anthropol Forum 15, 151-169.

34. Stewart I, for the Australian Medical Association (1997) Research into the Cost, Availability and Preferences for Fresh Food Compared with Convenience Food Items in Remote Area Aboriginal Communities. Canberra, ACT: Roy Morgan Research Centre.

35. King M (2015) Contextualization of socio-culturally meaningful data. Can J Public Health 106, e457.

36. Creswell JW (2013) Research Design: Qualitative, Quantitative, and Mixed Methods Approaches. Thousand Oaks, CA: SAGE Publications, Inc.

37. Brimblecombe JK (2007) Enough for Rations and a Little Bit Extra. Darwin, NT: Institute of Advanced Studies, Charles Darwin University.

38. Donahoo F \& Ross K (2015) Principles relevant to health research among Indigenous communities. Int J Environ Res Public Health 12, 5304-5309.

39. Bronfenbrenner U \& Morris PA (2006) The bioecological model of human development. In Handbook of Child Psychology: Theoretical Models of Human Development, 5th ed., vol. 1, pp. 993-1028 [W Damon and R Lerner, editors]. New York: Wiley.

40. Rasmussen M, Krølner R, Klepp K-I et al. (2006) Determinants of fruit and vegetable consumption among children and adolescents: a review of the literature. Part I: quantitative studies. Int J Behav Nutr Phys Act 3, 22.

41. Klepp K-I, Pérez-Rodrigo C, De Bourdeaudhuij I et al. (2005) Promoting fruit and vegetable consumption among European schoolchildren: rationale, conceptualization and design of the Pro Children project. Ann Nutr Metab 49, 212-220.

42. Thurber KA, Banks E \& Banwell C (2014) Cohort profile: Footprints in Time, the Australian Longitudinal Study of Indigenous Children. Int J Epidemiol 44, 789-800.

43. Hewitt B (2012) The Longitudinal Study of Indigenous Children: Implications of the Study Design for Analysis and Results. LSIC Technical Report. St Lucia, QLD: Institute for Social Science Research.

44. Bessarab D \& Ng'andu B (2010) Yarning about yarning as a legitimate method in Indigenous research. Int J Crit Indigenous Stud 3, 37-50.

45. Williamson A, Redman S, Dadds M et al. (2010) Acceptability of an emotional and behavioural screening tool for children in Aboriginal Community Controlled Health Services in urban NSW. Aust N Z J Psychiatry 44, 894-900.

46. Williamson A, McElduff P, Dadds M et al. (2014) The construct validity of the Strengths and Difficulties Questionnaire for Aboriginal children living in urban New South Wales, Australia. Aust Psychol 49, 163-170.

47. De Onis M \& Lobstein T (2010) Defining obesity risk status in the general childhood population: which cut-offs should we use? Int J Pediatr Obes 5, 458-460.

48. Thurber K, Banks E \& Banwell C (2014) Approaches to maximising the accuracy of anthropometric data on children: review and empirical evaluation using the Australian Longitudinal Study of Indigenous Children. Public Health Res Pract 25, e2511407.

49. Biddle N (2011) An Exploratory Analysis of the Longitudinal Survey of Indigenous Children. CAEPR Working Paper no. 77/2011. Canberra, ACT: Centre for Aboriginal Economic Policy Research.

50. Department of Health and Aged Care \& National Key Centre for Social Applications of Geographical Information Systems (2001) Measuring Remoteness: Accessibility/Remoteness Index of Australia (ARIA). Adelaide, SA: Commonwealth of Australia.

51. Biddle N (2009) Ranking Regions: Revisiting an Index of Relative Indigenous Socioeconomic Outcomes. Canberra, ACT: Centre for Aboriginal Economic Policy Research.

52. Blaikie N (2010) Designing Social Research, 2nd ed. Malden, MA: Polity Press.

53. Strauss AL (1987) Qualitative Analysis for Social Scientists. Cambridge: Cambridge University Press.

54. Timperio A, Ball K, Roberts R et al. (2008) Children's fruit and vegetable intake: associations with the neighbourhood food environment. Prev Med 46, 331-335.

55. Lee AJ, Kane S, Ramsey R et al. (2016) Testing the price and affordability of healthy and current (unhealthy) diets and the potential impacts of policy change in Australia. BMC Public Health 16, 315.

56. Burns C \& Inglis A (2007) Measuring food access in Melbourne: access to healthy and fast foods by car, bus and foot in an urban municipality in Melbourne. Health Place 13, 877-885.

57. Ball K, Timperio A \& Crawford D (2009) Neighbourhood socioeconomic inequalities in food access and affordability. Health Place 15, 578-585.

58. Barosh L, Friel S, Engelhardt K et al. (2014) The cost of a healthy and sustainable diet - who can afford it? Aust $N Z J$ Public Health 38, 7-12.

59. Winkler E, Turrell G \& Patterson C (2006) Does living in a disadvantaged area entail limited opportunities to purchase fresh fruit and vegetables in terms of price, availability, and variety? Findings from the Brisbane Food Study. Health Place 12, 741-748.

60. Palermo C, McCartan J, Kleve S et al. (2016) A longitudinal study of the cost of food in Victoria influenced by geography and nutritional quality. Aust N Z J Public Health 40, 270-273.

61. Rao M, Afshin A, Singh G et al. (2013) Do healthier foods and diet patterns cost more than less healthy options? A systematic review and meta-analysis. BMJ Open 3, e004277.

62. Brimblecombe JK \& O'Dea K (2009) The role of energy cost in food choices for an Aboriginal population in northern Australia. Med J Aust 190, 549-551.

63. Darmon N \& Drewnowski A (2008) Does social class predict diet quality? Am J Clin Nutr 87, 1107-1117.

64. Waterworth P, Dimmock J, Pescud M et al. (2016) Factors affecting Indigenous West Australians' health behavior: Indigenous perspectives. Qual Health Res 26, 55-68.

65. Lee A, Mhurchu CN, Sacks G et al. (2013) Monitoring the price and affordability of foods and diets globally. Obes Rev 14, 82-95. 
66. Andersen MJ, Williamson AB, Fernando P et al. (2016) 'There's a housing crisis going on in Sydney for Aboriginal people': focus group accounts of housing and perceived associations with health. BMC Public Health 16, 429.

67. Australian Bureau of Statistics (2008) 4704.0 - The Health and Welfare of Australia's Aboriginal and Torres Strait Islander Peoples, 2008: Housing and health. http://www. abs.gov.au/ausstats/abs@.nsf/0/F4302CEC55D5B8EECA257 4390014A785?opendocument (accessed April 2016).

68. Australian Institute of Health and Welfare (2014) Housing Circumstances of Indigenous Households: Tenure and Overcrowding. Catalogue no. IHW 132. Canberra, ACT: AIHW.

69. Priest N, Paradies Y, Trenerry B et al. (2013) A systematic review of studies examining the relationship between reported racism and health and wellbeing for children and young people. Soc Sci Med 95 , 115-127.

70. Paradies YC (2006) Defining, conceptualizing and characterizing racism in health research. Crit Public Health 16, 143-157.

71. Ziersch AM, Gallaher G, Baum F et al. (2011) Responding to racism: insights on how racism can damage health from an urban study of Australian Aboriginal people. Soc Sci Med 73, 1045-1053.

72. Kelly Y, Becares L \& Nazroo J (2013) Associations between maternal experiences of racism and early child health and development: findings from the UK Millennium Cohort Study. J Epidemiol Community Health 67, 35-41.

73. Paradies YC \& Cunningham J (2012) The DRUID study: racism and self-assessed health status in an indigenous population. BMC Public Health 12, 131.

74. Taylor CM, Wernimont SM, Northstone K et al. (2015) Picky/fussy eating in children: review of definitions, assessment, prevalence and dietary intakes. Appetite 95, 349-359.

75. Birch LL (1999) Development of food preferences. Annu Rev Nutr 19, 41-62.

76. Brimblecombe J, Maypilama E, Colles S et al. (2014) Factors influencing food choice in an Australian Aboriginal community. Qual Health Res 24, 387-400.
77. Hamilton A (1981) Nature and Nurture: Aboriginal ChildRearing in North-Central Arnhem Land. Canberra, ACT: Australian Institute of Aboriginal and Torres Strait Island.

78. Kruske S, Belton S, Wardaguga M et al. (2012) Growing up our way the first year of life in remote aboriginal Australia. Qual Health Res 22, 777-787.

79. Byers L, Kulitja S, Lowell A et al. (2012) 'Hear our stories': child-rearing practices of a remote Australian Aboriginal community. Aust J Rural Health 20, 293-297.

80. Sultan-Khan M-E (2014) An Aboriginal perspective on the influences of food intake. MSc Thesis, University of Ottawa.

81. Lee L, Griffiths C, Glossop P et al. (2010) The Boomerangs Parenting Program for Aboriginal parents and their young children. Australas Psychiatry 18, 527-533.

82. Colles SL, Belton S \& Brimblecombe J (2016) Insights into nutritionists' practices and experiences in remote Australian Aboriginal communities. Aust NZJ Public Health 40, Suppl. 1, S7-S13.

83. Zucker N, Copeland W, Franz L et al. (2015) Psychological and psychosocial impairment in preschoolers with selective eating. Pediatrics 136, e582-e590.

84. McCormick V \& Markowitz G (2013) Picky eater or feeding disorder? Strategies for determining the difference. Adv NPS PAs 4, issue 3, 18-22.

85. Williams LK, Thornton L, Crawford D et al. (2012) Perceived quality and availability of fruit and vegetables are associated with perceptions of fruit and vegetable affordability among socio-economically disadvantaged women. Public Health Nutr 15, 1262-1267.

86. Te Velde SJ, Wind M, Van Lenthe FJ et al. (2006) Differences in fruit and vegetable intake and determinants of intakes between children of Dutch origin and non-Western ethnic minority children in the Netherlands - a cross sectional study. Int J Behav Nutr Phys Act 3, 31.

87. Walter M (2016) Social exclusion/inclusion for urban Aboriginal and Torres Strait Islander people. Soc Inclus 4, 68-76.

88. Browne J, Adams K \& Atkinson P (2016) Food and Nutrition Programs for Aboriginal and Torres Strait Islander Australians: What Works to Keep People Healthy and Strong? Issues Brief no 17. Canberra, ACT: Deeble Institute for Health Policy Research. 